Rev. Bras. Saúde Prod. Anim., Salvador, v.15, n.4, p.897-906 out./dez., 2014 http://www.rbspa.ufba.br ISSN 15199940

\title{
Aditivos alternativos a antibióticos para frangos de corte no período de 22 a 42 dias de idade
}

\author{
Alternative Additives for Antibiotics for broiler chickens from 22 to 42 days of age
}

\author{
RAMOS, Lidiana de Siqueira Nunes ${ }^{1 *}$; LOPES, João Batista ${ }^{2}$; RIBEIRO, Mabell Nery ${ }^{3}$; \\ SILVA, Francisco Eduardo Soares ${ }^{4}$; MERVAL, Ramon Rêgo ${ }^{3}$; ALBUQUERQUE, \\ Daniel Medeiros de Noronha ${ }^{1}$
}

\author{
${ }^{1}$ Instituto Federal de Educação, Ciência e Tecnologia do Piauí, Teresina, Piauí, Brasil. \\ ${ }^{2}$ Universidade Federal do Piauí, Centro de Ciências Agrárias, Departamento de Zootecnia, Teresina, \\ Piauí, Brasil. \\ ${ }^{3}$ Universidade Federal do Piauí, Centro de Ciências Agrárias, Programa de Pós-Graduação em Ciência \\ Animal, Teresina, Piauí, Brasil. \\ ${ }^{4}$ Cooperativa Mista de Avicultores do Piauí, Teresina, Piauí, Brasil. \\ *Endereço para correspondência: lidiana@ifpi.edu.br
}

\section{RESUMO}

A pesquisa foi conduzida para avaliar o desempenho, metabolizabilidade dos nutrientes e rendimento de carcaça e dos principais cortes comerciais de frangos de cortes alimentados com dietas contendo aditivos alternativos a antibióticos promotores de crescimento, no período de 22 a 42 dias. Os tratamentos foram constituídos de uma ração controle padrão para atender as exigências das aves em cada fase e os demais adicionados de antibiótico; probióticos, prebióticos e simbióticos, com quatro repetições. O uso de probiótico (Lactobacillus acidophilus, Streptococcus faecium e Bifidumbacterium bifidum), do prebiótico (mananoligossacarídeo - MOS) e simbióticos, em ração de frangos de corte, proporciona resultado semelhante ao uso do antibiótico avilamicina $12 \%$ para desempenho, rendimento de carcaça e cortes comerciais (peito, dorso, coxa, sobrecoxa, asas, entreasas), coeficiente de metabolizabilidade da matéria seca, da proteína bruta e da energia bruta, no período de 22 a 42 dias de idade, constituindo esses aditivos em alternativa importante na substituição dos antibióticos promotores de crescimento.

Palavras-chave: energia bruta, matéria seca, aves

\section{SUMMARY}

This research was conducted to evaluate the performance, metabolizability of nutrients and yield of carcass and the most commercial cuts of broiler chickens fed with diets containing antibiotic growth promoter, probiotics, prebiotic and symbiotics, in the period from 22 to 42 days of age. The experimental treatments were constituted of the basal diet to attempt the nutritional requirements of birds in each phase and others treatments were added of antibiotic; probiotics; prebiotic and symbiotics. The use of probiotic (Lactobacillus acidophilus, Streptococcus faecium and Bifidumbacterium bifidum), and prebiotic (mananoligossacarídeoMOS) and symbiotics in ration of broiler chicken feed, produce performance, carcass yield and yield of most of the commercial cuts (breast, back, thigh, drumstick, wings and wing drumette), as well as metabolizability coefficient of dry matter, crude protein and gross energy, similar to that achieved with the use of the antibiotic Avilamycin 12\%, during the period from 22 to 42 days of age. This way, these additives are important alternative in the substitution of antibiotics.

Keywords: dry matter, gross energy, birds 
Rev. Bras. Saúde Prod. Anim., Salvador, v.15, n.4, p.897-906 out./dez., 2014 http://www.rbspa.ufba.br ISSN 15199940

\section{INTRODUÇÃO}

A microbiota do trato digestório de frangos de corte tem relevante papel na digestão dos alimentos ingeridos. Desequilíbrios na composição da microbiota desses animais podem trazer transtornos no desempenho e na capacidade de aproveitamento dos nutrientes.

Como a avicultura de corte é sustentada por pintos comerciais produzidos em sistema de incubação com grande controle sanitário, fato relevante no desenvolvimento da avicultura brasileira, por outro lado, tem retardado o estabelecimento de uma microbiota intestinal para estes animais. Assim, em condições sanitárias desfavoráveis, as aves ao chegarem às granjas ficam susceptíveis a desafios por microorganismos patogênicos, podendo ter atraso no desempenho, principalmente, pelo desenvolvimento de patologias entéricas e respiratórias.

$\mathrm{Na}$ rotina das granjas, os antibióticos promotores de crescimento (APC) têm sido utilizados, como principal aditivo melhorador de desempenho em rações de frangos de corte, visando compensar as adversidades de alta lotação, estresse, más condições sanitárias, que interferem nos custo de produção das aves (FERKET, 2003). O uso indiscriminado dos APC para fins terapêuticos, por longos períodos, tem resultado em seleção de linhas bacterianas resistentes, expondo ao desafio sanitário tanto a saúde humana como a animal (MONTAGNE et al., 2003).

Assim, novas estratégias para melhorar o aproveitamento dos nutrientes vêm surgindo, como os produtos da biotecnologia como probióticos, prebióticos e simbióticos, visando substituir os tradicionais APC, por serem produtos naturais, atóxicos e que não induzem resistência bacteriana. Esses produtos podem ser utilizados na ração dos frangos de corte, com a perspectiva de estabilizar e manter uma determinada população bacteriana em condições ideais no trato digestório, sem interferir de forma negativa na sanidade, na absorção dos nutrientes das rações, no desempenho desses animais e na saúde dos consumidores.

Dessa forma, o presente estudo foi desenvolvido para avaliar o desempenho, a metabolizabilidade dos nutrientes, o rendimento de carcaça e de cortes comerciais de frangos de corte, alimentados com rações contendo APC (avilamicina 12\%), probióticos (Lactobacillus acidophilus, Streptococcus faecium e Bifidumbacterium bifidum), prebiótico (mananoligossacarídeo - MOS selecionado da parede celular de uma cepa de Saccharomyces cerevisiae) e probióticos + prebiótico (simbióticos), no período de 22 a 42 dias de idade.

\section{MATERIAL E MÉTODOS}

A pesquisa foi realizada no Departamento de Zootecnia do Centro de Ciências Agrárias da Universidade Federal do Piauí (DZO-CCA-UFPI), em Teresina, Piauí e divididos em dois ensaios, um de desempenho e outro de metabolizabilidade. Para o ensaio de desempenho, foram selecionados individualmente, 600 pintos machos com 22 dias de idade, da linhagem Ross, com peso médio de $950 \pm 45 \mathrm{~g}$, ressaltando-se que esses animais foram criados até 21 dias de idade em galpão convencional, sem prévia desinfecção, consumindo uma ração controle de acordo com a fase (Tabela 1), formulada para atender às exigências das aves (ROSTAGNO et al., 2011), sobre cama de palha de arroz previamente utilizada por um lote de 
Streptococcus faecium 3,5 x $10^{11}$ UFC/kg e Bifidumbacterium bifidum 3,5 $\mathrm{x} 10^{11} \mathrm{UFC} / \mathrm{kg}$ ), em que foram utilizados $2 \mathrm{~kg} /$ tonelada de ração. $\mathrm{O}$ prebiótico testado foi um mananoligossacarídeo (MOS), produzido a partir de parede celular de uma cepa selecionada de Saccharomyces cerevisiae, o qual foi adicionado na proporção de $1 \mathrm{~kg} /$ tonelada de ração. A inclusão de cada aditivo teste nas dietas experimentais foi realizada em substituição de parte do material inerte, de acordo com as recomendações dos fabricantes.

O manejo das aves em todo o período experimental foi de acordo com $\mathrm{o}$ manual de criação da linhagem Ross. As aves receberam água limpa e ração ad libitum, sistema de aquecimento com lâmpadas incandescentes nos dez primeiros dias e vacinação ocular contra a doença de gumboro aos oito dias de idade. O programa de luz foi contínuo e o monitoramento da temperatura e da umidade no interior do galpão foi feito diariamente por meio de termohigrômetro, à altura intermediária em relação aos boxes. A partir de doze dias de idade, foram acionados ventiladores para melhorar o conforto térmico das aves.

Foram avaliadas as variáveis de desempenho (ganho de peso, consumo de ração, conversão alimentar, viabilidade de criação e índice de eficiência produtiva) nas fases de 22 a 33 e 22 a 42 dias de idade.

Para determinação do consumo de ração (CR) e do ganho de peso (GP), as aves foram pesadas no início e ao final de cada fase experimental. $\mathrm{O} \mathrm{CR}$ foi calculado por diferença entre a quantidade de ração fornecida e as sobras das rações experimentais. A partir dos dados de CR e GP, foi calculada a conversão alimentar (CA) pelos animais. $\mathrm{O}$ índice de viabilidade da criação (VC) foi calculado pela subtração de 100 pelo valor da mortalidade (\%) encontrado, enquanto $\mathrm{o}$ índice de eficiência produtiva (IEP), pela fórmula IEP = $((\mathrm{GP} \times \mathrm{VC}) /($ dias ate $\mathrm{o}$ final do $\begin{array}{lllll}\text { experimento } & \mathrm{x} & \mathrm{CA})) & \mathrm{x} & 100\end{array}$ (STRINGHINI et al., 2006).

Aos 42 dias de idade, foram selecionadas duas aves, pelo peso médio, por unidade experimental, as quais foram identificadas por etiquetas plásticas numeradas, submetidas a um jejum de seis horas, pesadas e, em seguida, submetidas aos procedimentos normais de abate (atordoamento, sangria, depenagem e evisceração). $\mathrm{O}$ rendimento de carcaça em percentual (RC \%) foi calculado em relação ao peso vivo das aves antes do abate.

As carcaças evisceradas (sem cabeça e sem pés) foram submetidas a cortes comerciais (peito, dorso, coxas, sobrecoxas, asas e entreasas). As víceras comestíveis (fígado, coração e moela) foram separados para pesagem em balança digital, sendo que a moela foi pesada após a sua abertura e eliminação do conteúdo alimentar presente. $\mathrm{O}$ rendimento percentual dos cortes $\mathrm{e}$ vísceras comestíveis foram calculados em função do peso da carcaça eviscerada (sem cabeça e pés), pela fórmula $\% \mathrm{R}$ cortes ou vísceras $=($ Peso do corte ou víscera $\mathrm{x}$ 100)/Peso Carcaça.

Para o ensaio de metabolismo, no $22^{\circ}$ dia, 100 frangos machos, da linhagem Ross, foram distribuídos em gaiolas metabólicas, preparadas com comedouros e bebedouros tipo calha e bandejas coletoras das excretas, em delineamento de blocos casualizados, baseados no peso das aves, usando-se os mesmos tratamentos do ensaio de desempenho (Tabela 1), com quatro repetições. A unidade experimental foi representada por cinco aves, alojadas em cada gaiola metabólica, sendo 
Rev. Bras. Saúde Prod. Anim., Salvador, v.15, n.4, p.897-906 out./dez., 2014 http://www.rbspa.ufba.br ISSN 15199940

utilizado o método de coleta total de excretas sem uso de marcador.

O período experimental teve duração de 10 dias, sendo os cinco primeiros dias para adaptação dos frangos às gaiolas e às dietas experimentais e os cinco últimos para coleta das excretas.

O manejo foi similar ao do ensaio de desempenho. $\mathrm{Na}$ tentativa de promover desafio sanitário, criou-se um protocolo de trabalho, diariamente no turno da manhã, em que era preparada uma solução de $1000 \mathrm{~mL}$ de água limpa com $50 \mathrm{~g}$ da cama de palha de arroz reutilizada de lotes de animais com 42 dias de idade. Em seguida, misturava-se $100 \mathrm{~mL}$ da solução da cama reutilizada com $900 \mathrm{~mL}$ de água limpa, para ser fornecida aos animais.

Foram realizadas duas coletas totais diárias das excretas de cada unidade experimental, início da manhã e final da tarde, durante os cinco dias experimentais de coleta de cada fase. As excretas coletadas foram acondicionadas em sacos plásticos devidamente identificados, pesadas e armazenadas em freezer a $-5^{\circ} \mathrm{C}$, até o período final dos experimentos, para realização das análises laboratoriais de acordo com os procedimentos de Silva \& Queiroz (2002) e a determinação da energia bruta (EB).

Os cálculos dos coeficientes de metabolizabilidade dos nutrientes das rações, de acordo com as fórmulas: Nutriente metabolizável (g/dia) = nutriente consumido (g/dia) - nutriente excretado (g/dia); Nutriente metabolizável da ração $(\%)=$ [nutriente metabolizável (g/dia) / consumo de matéria seca (MS) da ração (g/dia)] x 100 e Coeficiente de metabolizabilidade $(\%)=$ [nutriente metabolizável (g/dia) / nutriente consumido (g/dia)] x $100 \mathrm{de}$ acordo com Matterson et al. (1965).

Os resultados dos dois ensaios foram submetidos à análise da variância, e para avaliar o efeito dos tratamentos foi aplicado o Teste de Tukey a 5\% de probabilidade para comparação de média de acordo com o PROC GLM do Statistical Analysis System. Adotou-se $\alpha=0,05$.

\section{RESULTADOS E DISCUSSÃO}

No ensaio de desempenho, constatou-se que os tratamentos interferiram $(\mathrm{P}<0,05)$ nas variáveis analisadas, exceto na viabilidade da criação (Tabela 2). Os animais alimentados com a ração controle apresentaram baixo consumo de ração $(3,013 \mathrm{~kg})$, o menor ganho de peso $(1,391 \mathrm{~kg})$ e a pior conversão alimentar $(2,17 \mathrm{~kg} / \mathrm{kg})$. Esse resultado pode estar relacionado ao desafio sanitário que foi imposto aos animais, ao serem criados sobre cama reutilizada, durante toda a criação, inclusive antes de receberem os tratamentos no período pré-experimental de 1 a 21 dias de idade. Neste sentido, Gaggìa et al. (2010) relatam que os probióticos e prebióticos afetam a microbiota digestiva de forma positiva, protegendo o organismo contra a colonização por bactérias patogênicas.

Os resultados encontrados para consumo de ração, ganho de peso e conversão alimentar para o grupo de animais alimentados de ração contendo APC, probiótico, prebiótico e simbiótico não apresentaram diferença entre si, semelhante aos resultados obtidos por Silva et. al. (2011), no período de 1 a 42 dias de idade.

Por outro lado Rocha et al. (2010) observaram diferença na conversão alimentar de frangos de corte alimentados sem aditivo (controle), com APC, ou probiótico, ou prebiótico, ou prebiótico+ácidos orgânicos na fase de 22 a 43 dias, com destaque para o 
Rev. Bras. Saúde Prod. Anim., Salvador, v.15, n.4, p.897-906 out./dez., 2014 http://www.rbspa.ufba.br ISSN 15199940

último que obteve a melhor conversão alimentar.

$\mathrm{O}$ tratamento com a ração adicionada de APC apresentou maior valor de ganho de peso $(1,631 \mathrm{~kg})$ e o menor na conversão alimentar (1,95 $\mathrm{kg} / \mathrm{kg})$, entretanto não diferiu $(\mathrm{P}>0,05)$ das aves alimentadas com rações contendo probióticos, prebiótico e simbióticos. Assim, os aditivos estudados apontaram como alternativa para substituição do antibiótico avilamicina $12 \%$ na ração de frango de corte para o período isolado de 22 a 42 dias de idade. Stefe et al. (2008) ressaltaram que os probióticos e prebióticos, cada vez mais ganham espaço na nutrição animal, com a perspectiva de melhorar o desempenho e de prevenir doenças. Também, os estudos de Faria Filho et al. (2006) sobre a eficácia da utilização de probióticos como promotores de crescimento na alimentação de frangos de corte, sugerem que os probióticos promovem melhores índices de ganho de peso e conversão alimentar tanto na fase inicial (1 a 28 dias) quanto em toda fase de criação (1 a 35-48 dias). Porém, Lorençon et al. (2007) destacam que os probióticos para alcançarem boa eficiência devem ser utilizados nos primeiros dias de vida dos pintinhos, especialmente, na primeira semana Esta condição promove a exclusão competitiva, estimulando bom equilíbrio entre os micro-organismos benéficos.

Constatou-se que os tratamentos testados interferiram $(\mathrm{P}<0,05)$ sobre $\mathrm{O}$ índice de eficiência produtiva (IEP), sendo que os frangos, alimentados com as rações contendo APC e grupo controle, obtiveram respectivamente, $\mathrm{o}$ maior $(397,37 \%)$ e o menor $(292,83 \%)$ IEP (Tabela 2).

Tabela 2. Desempenho de frangos de corte, no período isolado de 22 a 42 dias de idade, alimentados com diferentes aditivos alternativos a antibiótico promotor de crescimento

\begin{tabular}{lcccccc}
\hline \multirow{2}{*}{ Variáveis } & \multicolumn{5}{c}{ Tratamentos } & \multirow{2}{*}{ CV $(\%)$} \\
\cline { 2 - 6 } & Controle & Antibiótico & Probiótico & Prebiótico & Simbiótico & \\
\hline CR $(\mathrm{kg})$ & $3,013^{\mathrm{b}}$ & $3,172^{\mathrm{ab}}$ & $3,221^{\mathrm{a}}$ & $3,326^{\mathrm{a}}$ & $3,233^{\mathrm{a}}$ & 2,76 \\
GP $(\mathrm{kg})$ & $1,391^{\mathrm{b}}$ & $1,631^{\mathrm{a}}$ & $1,629^{\mathrm{a}}$ & $1,635^{\mathrm{a}}$ & $1,604^{\mathrm{ab}}$ & 6,05 \\
$\mathrm{CA}(\mathrm{kg} / \mathrm{kg})$ & $2,17^{\mathrm{a}}$ & $1,95^{\mathrm{b}}$ & $1,98^{\mathrm{ab}}$ & $2,03^{\mathrm{ab}}$ & $2,02^{\mathrm{ab}}$ & 4,42 \\
VC $(\%)$ & 95,00 & 99,17 & 96,00 & 97,50 & 96,00 & 4,13 \\
IEP $(\%)$ & $292,83^{\mathrm{b}}$ & $397,37^{\mathrm{a}}$ & $374,12^{\mathrm{ab}}$ & $373,48^{\mathrm{ab}}$ & $360,53^{\mathrm{ab}}$ & 11,61 \\
\hline
\end{tabular}

Médias seguidas por letras diferentes nas linhas diferem pelo teste de Tukey $(\mathrm{P}<0,05)$.

$\mathrm{CR}$ = consumo de ração; $\mathrm{GP}$ = ganho de peso; $\mathrm{CA}=$ conversão alimentar; $\mathrm{VC}=$ viabilidade de criação; IEP = índice de eficiência produtiva.

Nos parâmetros relacionados com características da carcaça, as rações testadas interferiram $(\mathrm{P}<0,05)$ apenas nos valores percentuais das coxas, fígado e moela (Tabela 3). Os resultados encontrados em parte corroboram com os achados de Aristides et al. (2012), que utilizando APC, probióticos, prebiótico e simbiotico não observaram diferenças significativas nos cortes comerciais de frangos (asas, pernas, peito e dorso) em nenhum dos tratamentos utilizados.

Segundo Silva et al. (2011), os rendimentos de carcaça, peito, coxa, sobrecoxa, asa e coração de frangos aos 42 dias de idade, não sofreram influência significativa dos antibióticos, probióticos e simbióticos adicionados às rações experimentais. Para Albino et al. 
Rev. Bras. Saúde Prod. Anim., Salvador, v.15, n.4, p.897-906 out./dez., 2014 http://www.rbspa.ufba.br ISSN 15199940

(2006), o uso de avilamicina, mananoligossacarídeos de alta concentração (MOS AT) ou MOS Standard (MOS ST) os dois últimos diferindo apenas na concentração e utilizados combinados ou não com avilamicina, melhoraram o rendimento percentual de peito, entretanto no presente trabalho não foi observado nos grupos testados respostas diferentes para a essa variável.

Tabela 3. Rendimento de carcaça, cortes e vísceras comestíveis de frangos de corte, abatidos aos 42 dias de idade, alimentados com rações contendo diferentes aditivos alternativos a antibiótico promotor de crescimento

\begin{tabular}{lcccccc}
\hline \multirow{2}{*}{ Variáveis $(\%)$} & \multicolumn{5}{c}{ Tratamentos } & \multirow{2}{*}{ CV (\%) } \\
\cline { 2 - 6 } & Controle & Antibiótico & Probiótico & Prebiótico & Simbióticos & \\
\hline RC & 75,72 & 75,12 & 74,85 & 73,41 & 74,32 & 1,70 \\
Peito & 32,64 & 31,13 & 31,18 & 31,44 & 30,97 & 4,32 \\
Dorso & 25,16 & 25,05 & 26,98 & 25,42 & 26,15 & 4,00 \\
Coxas & $12,89^{\mathrm{b}}$ & $13,70^{\mathrm{ab}}$ & $13,84^{\mathrm{ab}}$ & $14,03^{\mathrm{a}}$ & $13,79^{\mathrm{ab}}$ & 3,72 \\
Sobrecoxas & 10,54 & 11,11 & 10,35 & 10,11 & 10,05 & 5,03 \\
Asas & 5,21 & 5,15 & 5,15 & 5,21 & 5,15 & 4,36 \\
Entreasas & 5,23 & 5,09 & 5,24 & 5,23 & 4,99 & 6,36 \\
Coração & 0,39 & 0,35 & 0,36 & 0,42 & 0,41 & 16,66 \\
Fígado & $2,40^{\mathrm{b}}$ & $2,55^{\mathrm{ab}}$ & $2,31^{\mathrm{b}}$ & $2,79^{\mathrm{ab}}$ & $2,95^{\mathrm{a}}$ & 8,93 \\
Moela & $1,50^{\mathrm{b}}$ & $1,54^{\mathrm{ab}}$ & $1,59^{\mathrm{ab}}$ & $1,75^{\mathrm{a}}$ & $1,63^{\mathrm{ab}}$ & 6,32 \\
\hline Mola
\end{tabular}

Médias seguidas por letras diferentes nas linhas diferem pelo teste de Tukey $(\mathrm{P}<0,05)$.

$\mathrm{RC}=$ rendimento de carcaça (retirado cabeça e pés, contendo pescoço).

No ensaio de metabolismo de nutrientes, constatou-se que não houve diferença $(\mathrm{P}>0,05)$ nos coeficientes de metabolizabilidade da matéria seca, da energia bruta e da proteína bruta entre os tratamentos estudados (Tabela 4). Estes dados estão em consonância com o verificado por Santos et al. (2012) que comparando o uso de enzimas (xilanase+amilase), probióticos e associação destes, além de um grupo controle, na alimentação de frangos de corte na fase de crescimento, não observaram efeito dos aditivos sobre a metabolizabilidade da matéria seca, energia bruta e proteína bruta.

Tabela 4. Coeficiente de metabolizabilidade da matéria seca, da energia bruta e da proteína bruta e balanço de nitrogênio das rações para frangos de corte, no período de 22 a 32 dias de idade

\begin{tabular}{lcccccc}
\hline \multirow{2}{*}{ Variáveis analisadas } & \multicolumn{5}{c}{ Tratamentos } & CV \\
& Controle & Antibiótico & Probiótico & Prebiótico & Simbiótico & $(\%)$ \\
\hline Coef. Metab. MS (\%) & 76,64 & 75,56 & 75,96 & 75,85 & 75,94 & 1,16 \\
Coef. Metab. EB (\%) & 79,18 & 77,54 & 78,15 & 78,08 & 77,94 & 1,13 \\
Coef. Metab. PB (\%) & 64,93 & 62,9 & 64,59 & 63,41 & 61,99 & 2,45 \\
Balanço de nitrogênio (g/dia) & $2,45^{\mathrm{ab}}$ & $2,47^{\mathrm{a}}$ & $2,46^{\mathrm{a}}$ & $2,45^{\mathrm{ab}}$ & $2,31^{\mathrm{b}}$ & $2,69 \mathrm{~b}$ \\
\hline
\end{tabular}

Médias seguidas por letras diferentes nas linha, diferem pelo teste de Tukey $(\mathrm{P}<0,05)$. 
Rev. Bras. Saúde Prod. Anim., Salvador, v.15, n.4, p.897-906 out./dez., 2014 http://www.rbspa.ufba.br ISSN 15199940

O balanço de nitrogênio foi positivo para todos os tratamentos. Entretanto, o tratamento adicionado de simbióticos apresentou menor balanço de nitrogênio $(\mathrm{P}>0,05)$ em relação aos tratamentos com a adição de antibiótico e probiótico.

O desafio sanitário imposto às aves, no período de 22 a 32 dias de idade, não foi suficiente para que os animais do grupo controle tivessem resultados inferiores aos grupos dos demais tratamentos, em relação a todas as variáveis analisadas. Entretando, Traldi et al. (2007), ressalta que existem poucos estudos destinados a avaliar as características da cama reutilizada com probióticos nas dietas.

Os resultados obtidos nos ensaios de desempenho estão em consonância com as observações de Bitterncourt et al. (2011) ao relatarem a possibilidade dos probióticos serem utilizados em substituição aos APC, pois trata-se de um suplemento aditivo de ração não patogênico, que atua beneficamente no hospedeiro melhorando o equilíbrio microbiano do intestino, bem como o uso de associações de prebióticos com probióticos (simbióticos) como observado por Caramori Junior et al. (2008).

A restrição do uso de APC aumentou a susceptibilidade intestinal das aves à colonização de microorganismos patogênicos oriundos do alimento $\mathrm{e}$ ambiente causando piora no desempenho produtivo, gerando em consequência, perdas econômicas na produção avícola (CERVANTES, 2006). Assim, os aditivos estudados probiótico, prebiótico e simbióticos podem constituir alternativas relevantes na substituição dos APC, em dietas de frangos de corte no período de 22 a 42 dias.

O uso de APC, probiótico, prebiótico e simbiótico, em ração de frango de corte, melhora as variáveis de desempenho (consumo de ração, ganho de peso, conversão alimentar e índice de eficiência produtiva) em relação ao tratamento controle sem, no entanto, apresentarem diferença entre si.

O rendimento de coxa, fígado e moela são melhorados pelo uso dos aditivos testados em relação ao grupo controle, porém não melhora os rendimentos de carcaça, peito, dorso, sobrecoxas, asas e entre asas.

Os coeficientes de metabolizabilidade da matéria seca, da proteína bruta e da energia bruta não são afetados pelos tratamentos utilizados, já o balanço de nitrogênio é diminuído pelo uso de simbiótico, no período de 22 a 42 dias de idade.

\section{AGRADECIMENTOS}

Ao Conselho Nacional de Desenvolvimento Científico e Tecnológico - CNPq, pelo apoio financeiro, Edital Universal 2006 - Proc. 485943/2006-9.

\section{REFERÊNCIAS}

ALBINO, L.F.T.; FERES, F.A.; DIONIZIO, M.H.; ROSTAGNO, H.S.; VARGAS JUNIOR, J.G.; CARVALHO, D.C.O; GOMES, P.C; COSTA, C.H.R. Uso de prebióticos à base de mananoligossacarídeo em rações para frangos de corte. Revista Brasileira de Zootecnia, v.35, n.3, p.742-749, 2006.

ARISTIDES, L.G.A.; PAIAO, F.G.; MURATE, L.S.; OBA, A; The effects of biotic additives on growth performance and meat qaulities in broiler chickens.

International Journal of Poultry

Science, v.11, n.9, p.599-604, 2012. 
Rev. Bras. Saúde Prod. Anim., Salvador, v.15, n.4, p.897-906 out./dez., 2014 http://www.rbspa.ufba.br ISSN 15199940

BITTERNCOURT, L.C.; SILVA, C.C.; GARCIA, P.D.S.R.; DONATO, D.C.Z; ALBUQUERQUE, R.; ARAÚJO, L.F. Influence of a probiotic on broiler performance. Revista Brasileira de Zootecnia, v.40, n.12, p.2739-2743, 2011.

CARAMORI JUNIOR, J.G.; ROÇA, R.O. FRAGA, A.L.; VIEITES, F.M.; MOCELLI, L.; GONÇALVES, M.A. Efeito de simbiótico na ração inicial de frangos de corte sobre o desempenho, qualidade de carcaça e carne. Acta Scientiarum Animal Science, v.30, n. 1, p.17-23, 2008.

CERVANTES, H. La proibición de al Unión Europea sobre la adición de antibióticos a alimentos de animales para consumo humano. Indústria Avícola. 2006. Disponível em: $<$ http://www.wattpoultry.com>. Acesso em: 13 set. 2008.

FARIA FILHO, D.E.; TORRES, K.A.A.; FARIA, D.E.; CAMPOS, D.M.B; ROSA, P.S. Probiotics for broiler chickens in Brazil: systematic review and meta-analysis. Brazilian Journal of Poultry Science, v.8, n.2, p.89-98, 2006.

FERKET, P.R. Managing gut health in a world without antibiotics. In: ALLTECH'S 17TH EUROPEAN MIDDLE EASTERN AND AFRICAN LECTURE TOUR, 2003, England. Proceedings... England: Alltech UK, England, 2003.

GAGGİA, F.; MATTARELLI, P.; BIAVATI, B. Probiotics and prebiotics in animal feeding for safe food production. International Journal of Food Microbiology, v.141, n.1; p.1528, 2010.
LORENÇON, L.; NUNES, R.V.N.; POZZA, P.C.; POZZA, M.S.S.; APPELT M.D.; SILVA W.M.S. Utilização de promotores de crescimento para frangos de corte em rações fareladas e peletizadas. Acta Scientiarum Animal Science, v.29, n.2, p.151-158, 2007.

MATTERSON, L.S.; POTTER, L.M.; STUTZ, M.W.; SINGSEN, E.P. The metabolizable energy of feed ingredients for chickens. Storrs, University of Connecticut, Agricultural Experiment Station, Research Report, v.7, p.11-14, 1965.

MONTAGNE, L.; PLUSKE, J.R.; HAMPSON, D.J. A review of interactions between dietary fibre and the intestinal mucosa, and their consequences on digestive health in young nonruminant animals. Animal Feed Science and Technology, v.108, n.2, p.95-117. 2003.

ROCHA, A.P.; ABREU, R.D.; COSTA, M.C.; OLIVEIRA, ALBINATI, R.C.B; PAZ, A.S.; QUEIROZ, L.G.; PEDREIRA, T.M. prebióticos, ácidos orgânicos e probióticos em rações para frangos de corte. Revista Brasileira de Saúde e Produção Animal [online], v.11, n.3, p.793-801, 2010.

ROSTAGNO, H.S.; ALBINO, L.F.T.; DONZELE, J.L.; GOMES, P.C.; OLIVEIRA, R.F.M.; LOPES, D.C.; FERREIRA, A.S.; BARRETO, S.L.T. Tabelas brasileiras para aves e suinos: composição de alimentos e exigências nutricionais. 3.ed. Viçosa: Universidade Federal de Viçosa, 2011, 252p.

SANTOS, I.I.; KESSLER, A.M.; MENDES, J.F.; GIANFELICI, M.F.; KRÁS, R.V. Efeitos de probiótico e enzimas em dietas para frangos de corte na fase de crescimento. Biotemas, v.25, n.2, p.187-191, 2012. 
SILVA, D.J.; QUEIROZ, A.C. Análise de alimentos: métodos químicos e biológicos. 3.ed.Viçosa, MG:

Universidade Federal de Viçosa, 2002. 235 p.

SILVA, W.T.M.; NUNES, R.V.; POZZA, P.C.; POZZA, M.S.S; APPELT, M.D.; EYNG, C. Avaliação de inulina e probiótico para frangos de corte. Acta Scientiarum Animal Sciences, v.33, n.1, p.19-24, 2011.

STRINGHINI, J.H.; ANDRADE, M.L.; ANDRADE, L.; XAVIER, A.G.; CAFÉ, M.B.; LEANDRO, N.S.M. Desempenho, balanço e retenção de nutrientes e biometria dos órgãos digestivos de frangos de corte alimentados com diferentes níveis de proteína na ração pré-inicial. Revista Brasileira de Zootecnia, v.35, n.6, p.2350-2358, 2006.
STEFE, C. de A.; ALVES, M.I.R.; RIBEIRO, R.L. probióticos, prebióticos e simbióticos - artigo de revisão. Saúde \& Ambiente em Revista, v.3, n.1, p.16-33, 2008.

TRALDI, A.B.; OLIVEIRA, M.C.; DUARTE, K.F.; MORAES, W.M.B. Avaliação de probióticos na dieta de frangos de corte criados em cama nova ou reutilizada. Revista. Brasileira. Zootecnia, v.36, n.3, p.660-665, 2007.

Data de recebimento: 11/03/2014 Data de aprovação: 27/10/2014 